\title{
Avaliação da atividade antioxidante e inibitória da tirosinase das folhas de Dipteryx alata Vogel (Baru)
}

\author{
SILVÉRIO, M.D.O.'; CASTRO, C.F.S.'; MIRANDA, A.R. ${ }^{1,2}$ \\ ${ }^{1}$ Instituto Federal de Educação, Ciência e Tecnologia Goiano, Rodovia Sul Goiana, Km 01 - Zona Rural. CEP: \\ 75901-970, Rio Verde - Brasil. ${ }^{2}$ Universidade de Rio Verde - FESURV. *dalila.silverio@hotmail.com
}

\begin{abstract}
RESUMO: Nos últimos anos, uma quantidade substancial de evidências tem indicado o papel chave dos radicais livres e outros oxidantes como grandes responsáveis pelo envelhecimento e pelas doenças degenerativas associadas ao mesmo. Por outro lado, substâncias fenólicas são reconhecidamente detentoras de pronunciada atividade antioxidante, muitas vezes envolvidas em tratamentos de pigmentação que resultam em hiperpigmentação ou hipopigmentação cutânea. Para o tratamento desses problemas de pigmentação vários produtos cosméticos e farmacêuticos são utilizados, porém, não são totalmente eficazes ou seguros, o que justifica a intensa pesquisa na busca de novos agentes ativos, principalmente àqueles envolvidos na melanogênese, como a tirosinase. Considerando que algumas substâncias obtidas de plantas apresentam essa atividade, a flora brasileira constitui-se uma importante fonte de pesquisa de novas substâncias. Assim, este trabalho foi realizado para avaliar os fenóis (método de FolinCiocalteau), a atividade antioxidante (CE50) (método de seqüestro do radical livre DPPH), a capacidade de quelação dos íons cobre, e a capacidade de inibição da tirosinase do extrato das folhas da espécie Dipteryx alata Vogel. Os resultados de fenóis totais mostraram uma concentração de $112,3 \mathrm{mg}$ EAG. $\mathrm{g}^{-1}$ no extrato etanólico e $45 \mathrm{mg} \mathrm{EAG.g}^{-1}$ no extrato hexânico. A capacidade antioxidante dos extratos indica que o extrato etanólico, em comparação ao hexânico e ao BHT, possui maior teor de compostos antioxidantes, apresentando os respectivos valores sobre a quantidade de extrato necessária para decrescer a concentração inicial de DPPH em 50\%: 52,9 \pm 1,3 ppm, 169,1 $\pm 2,3$ ppm, e 181 6 ppm. Já a capacidade de quelação dos íons cobre mostrou que o extrato etanólico possui capacidade de quelação insignificante. No ensaio de inibição da tirosinase o extrato etanólico demonstrou um percentual de inibição da enzima de $42 \%$ após uma hora.
\end{abstract}

Palavras-chave: Dipteryx alata Vogel, DPPH, hiperpigmentação, tirosinase.

ABSTRACT: Antioxidant and inhibitory action on tyrosinase from Dipteryx alata Vogel (Baru) leaves. In recent years, a substantial amount of evidence has shown the key role of free radicals and other oxidants as largely responsible for aging and associated degenerative diseases. On the other hand, phenolic substances are known to hold pronounced antioxidant activity, often involved in pigmentation treatments, which result in skin hyperpigmentation or hypopigmentation. For the treatment of these pigmentation problems several cosmetic and pharmaceutical products have been used; however, they are not fully effective or safe, which justifies intense research to find new active agents, especially those involved in melanogenesis such as tyrosinase. Considering that some substances obtained from plants have this activity, the Brazilian flora constitutes an important source of research for new substances. Thus, this study was conducted to evaluate the phenols (Folin-Ciocalteau assay), the antioxidant activity (EC50) (DPPH free radical scavenging assay), the chelation capability of copper ions, and the inhibition capability of tyrosinase from leaf extract of the species Dipteryx alata Vogel. Results for total phenols showed concentration of $112.3 \mathrm{mg} \mathrm{GAE} . \mathrm{g}^{-1}$ in ethanol extract and $45 \mathrm{mg} \mathrm{GAE} . \mathrm{g}^{-1}$ in hexane extract. The antioxidant capacity of extracts indicates that ethanol extract, compared to hexane extract and $\mathrm{BHT}$, has higher content of antioxidant compounds, showing the respective values of the necessary amount of extract to decrease the initial DPPH concentration by $50 \%$ : $52.9 \pm 1.3 \mathrm{ppm}, 169.1 \pm 2.3 \mathrm{ppm}$ and $181 \pm 6 \mathrm{ppm}$. On the other hand, the chelation capacity of copper ions showed that the ethanol extract has insignificant chelation capacity. In the tyrosinase inhibition test, the ethanol extract had $42 \%$ enzyme inhibition after one hour.

Key words: Dipteryx alata Vogel, DPPH, hyperpigmentation, tyrosinase.

Recebido para publicação em 09/05/2012

Aceito para publicação em 23/07/2012

Rev. Bras. PI. Med., Botucatu, v.15, n.1, p.59-65, 2013. 


\section{INTRODUÇÃO}

Ocupando a posição de segundo maior bioma do Brasil, e um dos mais diversos, o cerrado se distribui em aproximadamente $21 \%$ do território nacional e abriga cerca de $33 \%$ da diversidade biológica brasileira. Devido ao grande número de espécies, ao alto grau de endemismo, e à intensa destruição de seus habitats, o Cerrado é considerado um hotspot mundial, ou seja, representa uma área prioritária de conservação da biodiversidade (Aguiar et al. 2004).

O gênero Dipteryx é constituído por 15 espécies que se destacam por serem utilizadas como plantas medicinais. São encontradas nas regiões amazônica, nordeste e central do Brasil, na Venezuela e na América Central (Costa Rica e Panamá). O baru possui grande importância devido a sua elevada ocorrência e por participar do modelo de exploração praticado pelos pequenos produtores rurais, onde ocorre a preservação da planta durante a abertura dos pastos (Corrêa et al. 2000). Trata-se de uma espécie com um cultivo muito promissor, pois pode ser usada para diversos fins, destacandose o uso na alimentação, na indústria madeireira, na arquitetura paisagística e na recuperação de áreas degradadas.

Os frutos de baru são colhidos de agosto a outubro, sendo que estes contêm uma semente marrom comestível que é chamada de amêndoa, considerada uma oleaginosa. A amêndoa de baru contém altos níveis de lipídios (cerca de $40 \%$ ) e proteínas (cerca de $30 \%$ ), apresenta boa digestibilidade e perfil de aminoácidos. A amêndoa de baru tem ainda um alto teor de minerais, principalmente: cálcio, ferro, magnésio, potássio e zinco (Sousa et al, 2011). Possui também importância medicinal, pois em 2002, a Ichimaru Pharcos Inc. solicitou patente de uma substância do óleo da semente de baru que atua inibindo a formação de melanina (Sano et al, 2004).

Diversas substâncias com atividade antioxidante presentes em plantas medicinais são comumente isoladas nos mais diversos tipos de vegetais onde os principais responsáveis por tal atividade são as substâncias fenólicas que atuam como sequestradores de radicais livres e como quelantes de metais, alertando assim para a importância desses compostos que podem ser utilizados em diversas patologias (Haslam, 1998).

Uma dessas patologias éa hiperpigmentação da pele, a qual pode ser dependente do aumento da atividade melanogênica de enzimas, como a tirosinase. A tirosinase é a enzima que desempenha um papel crítico na biossíntese de melanina e é considerada a enzima chave na coloração de pele, cabelo, olhos e no escurecimento de alimentos. A tirosinase é uma enzima que contém cobre e é amplamente presente em mamíferos, plantas e fungos, tendo muitos compostos fenólicos como substrato. Nos mamíferos, ela está envolvida na transformação da L-tirosina, para dopaquinona, que ocorre através de duas etapas: hidroxilação da L-tirosina, para L-3,4-dihidroxifenilalanina (L-DOPA), seguido da oxidação deste último para orto-quinona (dopaquinona). A dopaquinona será transformada posteriormente através de várias reações para produzir a melanina (marrom ou preta), que é responsável pela cor da pele de mamíferos (Okombi et al, 2006).

A melanina desempenha um papel importante na proteção da pele humana dos efeitos nocivos da radiação UV do sol. Ainda que a melanina tenha principalmente função de fotoproteção na pele humana, o acúmulo de uma quantidade anormal de melanina em diferentes partes específicas da pele pode ocorrer, resultando em manchas mais pigmentadas, podendo se tornar um problema estético (Chang, 2009).

Muitos compostos inibidores e ativadores da tirosinase têm se tornado cada vez mais importantes em produtos medicinais e cosméticos. Por exemplo, os inibidores da tirosinase são usados em medicamentos e cosméticos clareadores, ao passo que os compostos que tendem a aumentar a melanogênese, como ativadores de tirosinase podem proteger a pele humana contra o dano da radiação UV solar (Okombi et al, 2006).

Devido a grande utilização desses produtos, vários compostos naturais e sintéticos atuando como inibidores da tirosinase foram relatados, mas apenas alguns deles são usados como agentes de clareamento da pele, devido a questões de segurança. Por exemplo, arbutina e o ácido kójico estavam entre os mais populares antes da descoberta dos efeitos secundários graves, o que levou a limitação do seu uso humano (Okombi et al, 2006).

Com efeitos insatisfatórios no tratamento das hiperpigmentações como melasma, hiperpigmentação pós - inflamatória, lentigo senil e efélides, as terapias atuais, que incluem a hidroquinona, o ácido kójico e a vitamina $C$, têm demonstrado vários efeitos secundários, dentre os quais podemos citar alta citotoxicidade e mutagenicidade, pouca penetração na pele e a baixa estabilidade das formulações (Nerva et al, 2003).

Existem diversos relatos na literatura sobre a atividade inibitória da melanogênse por extratos de plantas (Macrini et al, 2009). O que aliado ao fato do Brasil possuir cerca de $20 \%$ da biodiversidade do mundo (Suffredini et al, 2004), motiva a prospecção por novos agentes na flora brasileira.

O objetivo deste trabalho foi determinar os

Rev. Bras. PI. Med., Botucatu, v.15, n.1, p.59-65, 2013. 
fenóis totais, a atividade antioxidante, a capacidade de quelação dos íons cobre e a capacidade de inibição da tirosinase presentes na espécie Dipteryx alata Vogel.

\section{MATERIAL E MÉTODO}

As folhas foram obtidas na Área de Preservação Ambiental do Bioma Cerrado da Universidade de Rio Verde - FESURV

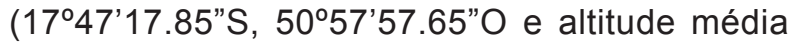
de $785 \mathrm{~m}$ ), sendo processadas no Laboratório de Química Tecnológica do Instituto Federal Goiano, campus Rio Verde e identificadas no Herbário Jataiense (HJ 3882).

As folhas foram secas em estufa na temperatura de $42^{\circ} \mathrm{C}$ até massa constante e trituradas na forma de um pó homogêneo. Cerca de $40 \mathrm{~g}$ do pó resultante foi transferido para erlenmayer e adicionado cerca de $400 \mathrm{~mL}$ de hexano, permanecendo a temperatura ambiente, por dois dias, em ambiente escuro. Após este período foi filtrado e destilado sob pressão reduzida. $O$ procedimento foi repetido por mais duas vezes com o solvente hexano obtendo-se desta forma o extrato bruto hexânico das folhas (EH).

Em seguida, o mesmo procedimento foi repetido utilizando-se etanol como solvente e obtendo-se o extrato bruto etanólico das folhas (EE). O rendimento dos extratos foi calculado pela expressão: Rendimento $(\%)=$ (massa do extrato/ massa do material vegetal) $\times 100$.

\section{Determinação de fenóis totais}

A determinação do teor de fenóis totais presentes nas amostras dos extratos das folhas foi realizada segundo o método de Folin-Ciocalteu com modificações (Bonoli et al, 2004). O extrato bruto $(100 \mathrm{mg}$ ) foi dissolvido em etanol, transferido quantitativamente para um balão volumétrico de $100 \mathrm{~mL}$ e o volume final foi completado com etanol. Uma alíquota de $100 \mu \mathrm{L}$ desta última solução foi agitada com $500 \mu \mathrm{L}$ do reagente de Folin-Ciocalteu e 6,4 $\mathrm{mL}$ de água destilada por $1 \mathrm{~min}$; passado este tempo, $2 \mathrm{~mL}$ de $\mathrm{Na}_{2} \mathrm{CO}_{3}$ a $15 \%$ foram adicionados à mistura e agitada por $30 \mathrm{~s}$. Após $2 \mathrm{~h}$, a absorbância das amostras foi medida a $750 \mathrm{~nm}$. O teor de fenóis totais (FT) foi determinado através de uma curva de calibração utilizando ácido gálico como padrão (10 a $350 \mu \mathrm{g} / \mathrm{mL}$ ) e expresso como $\mathrm{mg}$ de EAG (equivalentes de ácido gálico) por g de extrato. As análises foram realizadas em triplicata.

\section{Avaliação da atividade antioxidante pelo método do sequestro do radical livre DPPH (1,1-Diphenyl-2-picryl-hydrazil)}

A capacidade antioxidante foi avaliada segundo método descrito por Melo et al. (2006), usando o radical livre estável DPPH. Cerca de 2,0 $\mathrm{mg}$ de DPPH foram dissolvidos em $100 \mathrm{~mL}$ de etanol, resultando em uma solução de concentração 20 mg. $\mathrm{L}^{-1}(500 \mu \mathrm{M})$, com absorbância em torno de 0,4 U.

Alíquotas de volumes entre 0 e $1000 \mu \mathrm{L}$ das soluções estoque da amostra e de BHT foram transferidas, adicionando-se etanol, até completar o volume para $1 \mathrm{~mL}$. Em seguida, foram adicionados $4 \mathrm{~mL}$ da solução de DPPH. As misturas foram deixadas em repouso em um local escuro, por 30 minutos, e suas absorbâncias medidas a $517 \mathrm{~nm}$. Soluções de compensação foram feitas usando apenas etanol no lugar da solução de DPPH.

A capacidade antioxidante foi calculada pela equação abaixo como sendo o percentual de DPPH sequestrado em cada concentração:

$$
\% D P P H s e q=\frac{A b s(\text { Controle })-[A b s(\text { amostra })-A b s(\text { compensação })]}{A b s(\text { Controle })} \times 100
$$

Os dados obtidos foram usados para construir curvas de DPPH sequestrado versus a concentração da amostra, de modo a determinar a Concentração Efetiva 50 (CE50), ou seja, a concentração necessária para sequestrar metade do teor inicial de DPPH através da análise de regressão linear e interpolação dos mesmos.

Todas as medidas foram realizadas em três experimentos independentes, cada um em triplicata, e os resultados foram expressos em mg. $\mathrm{L}^{-1}$ como média e desvio padrão.

\section{Ensaio de inibição de tirosinase}

A tirosinase de cogumelo (Agaricus bisporus) e a L-tirosina foram adquiridos da Sigma Chemical Co e Vetec, respectivamente.

A atividade da tirosinase foi determinada por espectrofotometria conforme descrito por Khatib (2005), com adaptações. Foram preparadas 3 soluções: uma contendo $500 \mu \mathrm{L}$ de tampão fosfato (pH 7,0), $2 \mathrm{~mL}$ da tirosinase de cogumelo (200 U / $\mathrm{mL}$ ) e $50 \mu \mathrm{L}$ da amostra da solução com extrato etanólico da planta (1000 ppm), outra contendo 500 $\mu \mathrm{L}$ de tampão fosfato $(\mathrm{pH} 7,0), 2 \mathrm{~mL}$ da tirosinase de cogumelo (200 U / mL) e $50 \mu \mathrm{L}$ de etanol e outra contendo $500 \mu \mathrm{L}$ de tampão fosfato $(\mathrm{pH} 7,0), 2 \mathrm{~mL}$ da tirosinase de cogumelo $(200 \mathrm{U} / \mathrm{mL}$ ) e $50 \mu \mathrm{L}$ de ácido Kójico (1000 ppm). Após 5 minutos, 2 mL de solução 
de $2 \mathrm{mM}$ de L-tirosina foram adicionados a cada solução teste. A absorção a $475 \mathrm{~nm}$ foi monitorada em função do tempo realizando-se duas leituras: uma em 30 minutos, e outra, após 60 minutos. A variação da densidade ótica foi comparada na presença e ausência dos extratos para verificar a inibição da tirosinase.

\section{Quelação com íons $\mathrm{Cu}^{2+}$}

A capacidade quelante em relação aos íons $\mathrm{Cu}^{2+}$ do extrato etanólico foi avaliada por medidas de absorbância na faixa entre 260 a 500 $\mathrm{nm}$. Inicialmente incubou-se $500 \mu \mathrm{L}$ da solução do extrato etanólico da planta (1000 ppm), $500 \mu \mathrm{L}$ da solução de ácido Kójico (1000ppm) e 2 mL de tampão fosfato $(\mathrm{pH} \mathrm{6,5)} \mathrm{obtendo-se} 2$ amostras. Em seguida realizou-se a leitura da absorbância na faixa entre 260 a $500 \mathrm{~nm}$. Após a leitura adicionou-se $100 \mu \mathrm{L}$ da solução de $\mathrm{CuSO}_{4}$ nas amostras e realizou-se novamente a leitura da absorbância adicionando-se em seguida $100 \mu \mathrm{L}$ da solução de EDTA $(250 \mu \mathrm{M})$; então, novamente fez-se a leitura da absorbância, verificando a formação ou não de complexos através da alteração das medidas de absorbância.

\section{Análise estatística}

Os resultados foram apresentados como médias e desvios padrão de três ensaios independentes. O programa estatístico utilizado foi o SISVAR. Dados com $p<0,05$ foram considerados significativos.

\section{RESULTADO E DISCUSSÃO}

O método de Folin-Ciocalteau permite quantificar compostos fenólicos presentes nas amostras. A Tabela 1 demonstra a quantidade total de fenóis dos extratos das folhas obtidas por extração hexânica e etanólica. A fração etanólica apresentou maior quantidade de compostos fenólicos com teor de 112,3 mg EAG.g-1. Já a fração hexânica apresentou menor teor, de $45,0 \mathrm{mg}$ EAG. $\mathrm{g}^{-1}$. Estes teores foram obtidos a partir da curva de calibração com ácido gálico, cuja concentração é dada pela equação:

Abs $=0,0012 \times$ (Conc Ácido Gálico, ppm) $-0,0007, R=0,9995$.

TABELA 1. Teor de Fenóis Totais expressos em Equivalentes de Ácido Gálico (EAG).

\begin{tabular}{ll}
\hline Extração & Fenóis Totais (mg EAG.g-1 $\left.{ }^{-1} \mathbf{m s}\right)$ \\
\hline Etanólica & $112,3 \pm 5,1 \mathrm{a}$ \\
Hexânica & $45,0 \pm 7,6 \mathrm{~b}$
\end{tabular}

*ms: massa seca

Letras minúsculas iguais indicam equivalência estatística pelo SISVAR. Ambos ao nível $5 \%$ de significância.
A quantidade necessária de extrato das plantas testadas para decrescer a concentração inicial de DPPH em 50\%, CE50, apresentada na tabela 2, foi de $52,9 \mathrm{ppm}, 169,1 \mathrm{ppm}$ e $181 \mathrm{ppm}$ para os extratos etanólico, hexânico e para o $\mathrm{BHT}$, respectivamente. O BHT é um antioxidante comercial, amplamente disponível e utilizado em diversos produtos e formulações. Os extratos obtidos apresentaram uma CE50 comparavél ao $\mathrm{BHT}$, indicando a presença de compostos com atividade antioxidante significativa nos mesmos. Além disto, nota-se que os compostos com atividade antioxidante concentram-se preferencialmente no extrato mais polar (etanol), enquanto que os compostos mais apolares não apresentam atividade antioxidante significativa. O extrato etanólico apresenta uma CE50 significativa, constituindo uma possível fonte de compostos antioxidantes, já que mostrou uma atividade maior do que o BHT.

TABELA 2. Atividade Antioxidante dos Extratos Etanólico e Hexânico.

\begin{tabular}{lc}
\hline Extratos & $\begin{array}{c}\text { Quantidade de extrato } \\
\text { necessária para decrescer a } \\
\text { concentração inicial de DPPH } \\
\text { em } \mathbf{5 0 \%} \text { (CE50) (ppm). }\end{array}$ \\
\hline Etanólico & $52,9 \pm 1,3 \mathrm{a}$ \\
Hexânico & $169,1 \pm 2,3 \mathrm{~b}$ \\
BHT & $181 \pm 6 \mathrm{c}$ \\
\hline
\end{tabular}

Letras minúsculas iguais indicam equivalência estatística pelo SISVAR.

Ambos ao nível $5 \%$ de significância.

Atualmente, diversos estudos epidemiológicos mostram que os compostos fenólicos constituem uma das classes mais abundantes no reino vegetal, e possuem múltiplos efeitos biológicos (Rao, 2003).

Vários antioxidantes naturais já foram isolados de diferentes tipos de materiais vegetais, como sementes oleaginosas, cereais, legumes, frutas, folhas, raízes, temperos e ervas (Ramarathnam et al, 1995). Embora compostos antioxidantes tenham sido identificados nas sementes de citros (Alessandra et al, 1998), uva (Jayaprakasha et al, 2001), manga (Puravankara et al, 2000), canola (Krygier et al, 1982; Naczk et al, 1998; Wanasundara et al, 1994), girassol (Kubicka et al, 1999), prímula (Balasinska \& Troszynska, 1998; Wettasinghe \& Shahidi, 1999), gergelim (Shahidi et al, 1997), linhaça (Oomah et al, 1995) e tremoço (Tsaliki et al, 1999), estudos relacionados com a atividade antioxidante de sementes de frutas tropicais e subtropicais ainda têm sido pouco relatados. 
Outros trabalhos também mostram que muitos compostos fenólicos presentes em plantas apresentam atividade inibitória da tirosinase (Sugumaran, 2002; Boissy \& Manga, 2004; Victor et al, 2004).

Por isso, o extrato escolhido para o teste de inibição da tirosinase foi o etanólico, que apresentou teor maior de compostos fenólicos. Há também relatos de que compostos fenólicos podem ser usados como agentes despigmentantes, devido ao fato de possuírem uma estrutura química semelhante a da tirosina, o substrato da tirosinase (Boissy \& Manga, 2004). Portanto, a potência das substâncias utilizadas como agentes despigmentantes da pele se deve, pelo menos em parte, pela ação de componentes fenólicos (Wang et al, 2006).

O ensaio para quantificar a atividade inibitória do extrato etanólico indicou uma inibição de $42 \%$ após uma hora, enquanto que o controle positivo - ácido kójico - inibiu completamente a enzima, chegando a apresentar valores negativos.

A pele uniforme e sem manchas é uma característica estética importante, por isso, problemas de pigmentação tais como a presença de manchas podem afetar a autoestima de um indivíduo; porém, existem tratamentos que amenizam esse problema. Nos últimos anos houve um acréscimo significativo na quantidade de produtos disponíveis no mercado que são usados para o clareamento da pele; contudo, as terapias não têm demonstrado bons resultados. Isto se deve a alta toxicidade das substâncias de branqueamento como observado para a hidroquinona (Grimes, 1999), o que estimula a necessidade de pesquisas com a intenção de nomear novas substâncias despigmentantes (Macrini et al, 2009).

Existem muitas substâncias capazes de inibir a atividade da enzima tirosinase por meio de vários mecanismos. Por exemplo, o ácido ascórbico, que é usado como um inibidor da melanogênese por causa de sua capacidade de conversão da dopaquinona a dopa, evitando formações de melanina. Outra possibilidade corresponde aos substratos alternativos desta enzima, como alguns compostos fenólicos, que ao mostrarem uma boa afinidade pela mesma, impedem a formação do dopacromo. Podem ser relatados também os inativadores inespecíficos da enzima, tais como ácidos ou bases, que não especificamente desnaturam a enzima, mas inibem sua atividade. Os inativadores específicos da tirosinase, tais como inibidores baseados em mecanismo, que também são chamados de substratos suicídio, que inativam irreversivelmente a enzima durante a reação catalítica. Os inibidores específicos da tirosinase são os compostos que se ligam reversivelmente a tirosinase e reduzem sua capacidade catalítica. Entre os tipos de compostos descritos acima, só os inativadores de tirosinase específicos e inibidores são considerados como "inibidores de verdade", que se ligam à enzima e inibem sua atividade. De maneira geral, os demais inibidores apresentam apenas atividade inibitória fraca (Chang, 2009).

Os "inibidores de verdade" são classificados em quatro tipos, que são: inibidores competitivos (uma substância que se mistura com uma enzima livre de maneira que impeça a ligação do substrato), inibição incompetitiva, por exemplo, os quelantes de cobre; inibidores não competitivos (se ligam apenas com o complexo enzima-substrato); tipo misto de inibidores (competitivo/não competitivos) (Chang, 2009).

A capacidade de quelação dos íons cobre não apresentou resultados significativos (ver Tabela 4), pois observa-se que não ocorreu deslocamento dos picos máximos com a adição do cobre, enquanto que tal fato ocorreu na solução de ácido kójico. Tal fato mostra que a inibição da enzima apresentada no extrato etanólico das folhas não ocorre por ação de inibidores incompetitivos por quelação de cobre. Mostrando assim que a inibição ocorre possivelmente devido ao extrato etanólico apresentar quantidades significativas de compostos fenólicos, que, por possuírem estrutura semelhante a da tirosina, que é um substrato da enzima, se apresentam como substrato alternativo a enzima. Entretanto, não sendo oxidados, competem com a tirosina (Germanò et al, 2012; Wu et al, 2003).

Os dados obtidos para os fenóis totais e atividade antioxidante indicam que os compostos secundários concentram-se preferencialmente no extrato polar (etanólico) das folhas de Dipteryx alata Vogel, provavelmente tendo polifenóis como constituintes. Por isso, os testes de quelação e inibição da tirosinase foram realizados somente

TABELA 4. Picos máximos de absorção antes e após a adição de solução de Cobre.

\begin{tabular}{lll}
\hline Pico máximo & Pico máximo & \\
\hline Ácido Kójico & $270 \mathrm{~nm}$ & \\
Ácido kójico + Solução de Cobre & $310 \mathrm{~nm}$ & \\
Extrato & $325 \mathrm{~nm}$ & $410 \mathrm{~nm}$ \\
Extrato + Solução de Cobre & $325 \mathrm{~nm}$ & $410 \mathrm{~nm}$ \\
\hline
\end{tabular}

Rev. Bras. PI. Med., Botucatu, v.15, n.1, p.59-65, 2013. 
neste extrato, que demonstrou possuir capacidade de quelação dos íons cobre insignificante e certa capacidade de inibir a tirosinase nos testes in vitro por espectrofotometria.

Devido a grande necessidade de novas substâncias despigmentantes, que realmente sejam eficazes e não tragam tantos efeitos nocivos à saúde, é muito interessante estudar novas substâncias obtidas a partir da exploração de plantas do cerrado brasileiro, como o baru. De fato o cerrado é composto por grande biodiversidade vegetal que merece ser estudada com o objetivo de nomear plantas potenciais que inibam a enzima tirosinase e que possam substituir efetivamente os compostos sintéticos encontrados no mercado.

Por se tratar de um extrato bruto etanólico, existem inúmeras substâncias que podem ser responsáveis por tal capacidade; por isso, os resultados descritos neste trabalho estimulam a continuidade dos estudos dos compostos presentes no extrato etanólico com a intenção de isolar e identificar as substâncias responsáveis pela ação antioxidante e inibidora da tirosinase presentes no baru. Tal extrato pode se tratar de um interessante candidato para a avaliação de ensaios biológicos mais complexos, tais como toxicidade in vitro, culturas de melanócitos e, eventualmente, testes em humanos em ensaios in vivo.

\section{AGRADECIMENTOS}

Os autores agradecem a Capes pela concessão de bolsa e pelo auxílio financeiro, que são de extrema importância para a execução das pesquisas.

\section{REFERÊNCIA}

AGUIAR, L.M.S.; MACHADO R.B.; MARINHO-FILHO J. A diversidade biológica do Cerrado. In: L.M.S. Aguiar \& A. Camargo (eds.). Ecologia e caracterização do Cerrado. 2004, pp. 19-42.

ALESSANDRA, B.; MARIE-ELISABETH, C.; HUBERT, R.; CLAUDETTE, B. Antioxidant activity and phenolic composition of citrus peel and seed extracts. Journal of Agricultural and Food Chemistry, v. 46, p. 2123-2129, 1998.

BALASINSKA, B.; TROSZYNSKA, A. Total antioxidant activity of evening primrose (Oenotheraparadoxa) cake extract measured in vitro by liposome model and murine L1210 cells. Journal of Agricultural and Food Chemistry, v. 46, p. 3558-3563, 1998.

BOISSY, R.E.; MANGA, P. On the etiology of contact/ occupational vitiligo. Pigment Cell Research. v. 17, p. 208-214, 2004.

BONOLI, M.; VERARDO, V.; MARCONI, E.; CABONI, M. F.; Journal of Agricultural and Food Chemistry, v. 52, p. 5195, 2004.

CHANG, TE-SHENG. An Updated Review of Tyrosinase
Inhibitors. International Journal of Molecular Sciences, v. 10, p.2440-2475, 2009.

CORREAA, G. C.; NAVES, R. V.; ROCHA, M. R.; ZICA, L. F. Caracterização física de frutos de baru (Dipteryx alata Vog.) em três populações nos cerrados do Estado de Goiás. Pesquisa AgropecuáriaTropical, v. 30, n. 2, p. 5-11, 2000

GERMANÒ, M.P.; CACCIOLA, F.; DONATO, P.; DUGO, P.; CERTO, G.; D’ANGELO, V.; MONDELLO, L.; RAPISARDA, A. Betula pendula leaves: Polyphenolic characterization and potential innovative use in skin whitening products. Fitoterapia, v. 83. pp. 877-822, 2012. GRIMES, P. E. The safety and efficacy of salicylic acid chemical peels in darker racial-ethnic groups. Dermatologic Surgery, v. 25, p.18-22, 1999.

HASLAM, E. Practical Polyphenolics from structure to molecular recognition and physiological action, Cambridge University Press: Cambridge, 1998, 103p.

JAYAPRAKASHA, G. K.; SINGH, R. P.; SAKARIAH, K. K. Antioxidant activity of grape seed (Vitisvinifera) extracts on peroxidation models in vitro. Food Chemistry, v. 73, p. 285-290, 2001.

KHATIB, S.; NERYA, O.; MUSA, R.; SHMUEL, M.; TAMIR, S.; VAYA, J. Chalcones as potent tyrosinase inhibitors: the importance of a 2,4-substituted resorcinol moiety. Bioorganic \& Medicinal Chemistry. v. 13, p. 433-441, 2005.

KRYGIER, K.; SOSULSKI, F.;HOGGE, L. Free, esterified, and insoluble-bound phenolic acids. 1. Extraction and purification procedure. Food Chemistry, v. 30, p. 330334, 1982.

KUBICKA, E.; JEDRYCHOWSKI, L.; AMAROWICZ, R. Effect of phenolic compounds extracted from sunflower seeds on native lipoxygenase activity.Grasas y Aceites, v. 50, p. 3206-3209, 1999.

MACRINI, D. J.; SUFFREDINI I. B.; VARELLA A. D., YOUNES R N.; OHARA M. T. Extracts from Amazonian plants have inhibitory activity against tyrosinase: an in vitro evaluation. Brazilian Journal of Pharmaceutical Sciences, v. 45, n. 2, 2009.

MELO, E. A.; MACIEL, M. I. S.; LIMA, V. L. A. G.; LEAL, F. L. L., CAETANO A. C. S., NASCIMENTO, R. J. Capacidade antioxidante de hortaliças usualmente consumidas. Ciência e Tecnologia de Alimentos, v. 26, n.3, p. 639-644, 2006.

NACZK, M.; AMAROVICZ, R.; SULLIVAN, A.;SHAHIDI, F. Currentresearchdevelopmentsonpolyphenolicsofrapeseed/canola, a review. Journal of Agricultural and Food Chemistry, v. 62, p. 489-502, 1998.

NERVA, O.; MUSA, R.; IZRAEL, S.; TAMIR, S. Glabrene and isoliquiritigenin as tyrosinase inhibitors from licorice roots. Journal of Agricultural and Food Chemistry, v.51, p.1201-1207, 2003.

OKOMBI S.; RIVAL D.; BONNET S.; MARIOTTE A. M. ; PERRIERB E.; BOUMENDJEL A. Analogues of $\mathrm{N}$-hydroxycinnamoylphenalkylamides as inhibitors of human melanocyte-tyrosinase. Bioorganic \& Medicinal Chemistry Letters, v.16, n. 8, p. 2252-2255, 2006.

OOMAH, B. D.; KENASCHUK, E. O.; MAZZA, G. Phenolic acids in flaxseed. Journal of Agricultural and Food Chemistry, v. 43, p. 2019-2026, 1995.

PURAVANKARA, D.; BOGHRA, V.;SHARMA, R. S. Effect of antioxidant principles isolated from mango (Mangifera 
indica L.) seed kernels on oxidative stability of buffalo ghee (butter-fat). Journal of the Science of Food and Agriculture, v.80, p. 522-526, 2000.

RAMARATHNAM, N.; OSAWA, T.;OCHI, H.; KAWAKISHI, $S$. The contribution of plant food antioxidants to human health. Trends in Food Science and Technology, v. 6 , p. 75-82, 1995.

RAO, B. Bioactive phytochemicals in Indian foods and their potential in health promotion and disease prevention. Asia Pacific Journal of Clinical Nutrition.v.12, p. 9-22, 2003. SANO, S. M.; RIBEIRO, J.F.; BRITO, M. A. de. Baru: biologia e uso. Planaltina: Embrapa Cerrados, 2004, 52p. SOUSA, A. G. O.; FERNANDES D. C.; ALVES A. M.; FREITAS J. B.; NAVES M. M. V. Nutritional quality and protein value of exotic almonds and nut from the Brazilian Savanna compared to peanut. Food Research International, v. 44, p. 827- 834, 2011.

SUFFREDINI, I. B.; SADER, H. S.; GONÇALVES, A. G.; REIS, A. O.; GALES, A. C.; VARELLA, A. D.; YOUNES, R. N. Screening of antibacterial active extracts obtained from plants native to Brazilian Amazon rain forest and Atlantic forest. Brazilian Journal of Medical and Biological Research, v. 37, p.379-384, 2004.

SUGUMARAN, M. Comparative biochemistry of eumelanogenesis and theprotective roles of phenoloxidase and melanin in insects. Pigment Cell Research, v. 15, p.2-9, 2002.

TSALIKI, E.; LAGOURI, V.;DOXASTAKIS, G. Evaluation of the antioxidant activity of lupin seed flour and derivatives (Lupinusalbus ssp. Graecus). Food Chemistry,v. 65, p. 71-75, 1999.

VICTOR, F.C.;GELBER, J.;RAO, B. Melasma: a review. Journal of Cutaneous Medicine and Surgery,v. 8, p.97-102, 2004.

WANG K.; LIN R.; HSUD F.; HUANGE Y.; HANGF H.; HUANGD C.; LEE M. Cosmetic applications of selected traditional Chinese herbal medicines. Journal of Ethnopharmacology. v. 106, n. 3, p. 353-359, 2006. WETTASINGHE, M.; SHAHIDI, F. Evening primrose meal, a source of natural antioxidants and scavenger of hydrogen peroxide and oxygen-derived free radicals. Journal of Agricultural and Food Chemistry, v. 47, p. 1801-1812, 1999.

WANASUNDARA, U. N.; AMAROVICZ, R.; SHAHIDI, F. Isolation and identification of an antioxidative component in canola. Journal of Agricultural and Food Chemistry, v. 42, p. 1285-1290, 1994.

WU, LI-CHEN; CHEN, Y UN-CHEN; HO, J A-AN ANNIE; YANG, ANDCHUNG -SHI. Inhibitory Effect of Red Koji Extracts on Mushroom Tyrosinase. Journal of Agricultural and Food Chemistry, v. 51, pp. 4240 “4246, 2003. 